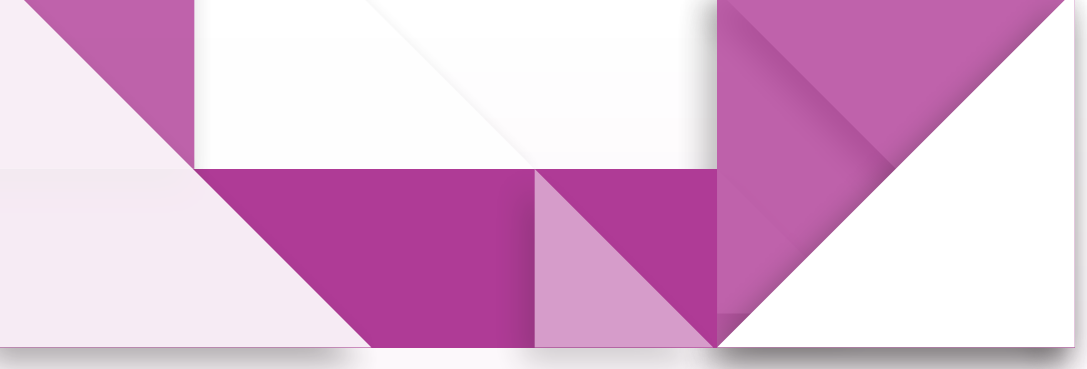

\title{
Decomposição e ciclagem 3 de nutrientes: uma análise da abordagem do livro didático e da prática docente no ensino médio
}

- Decomposition and Nutrient Cycling: An Analysis of the Approach of Textbooks and of the Teaching Practice in Secondary Education

- Descomposición y ciclaje de nutrientes: un análisis del abordaje del libro didáctico y de la práctica docente en la enseñanza media

\begin{abstract}
Resumo
O artigo objetivou investigar como o conteúdo envolvendo a decomposição e ciclagem de nutrientes é abordado no Ensino Médio (EM) pelo professor e no livro didático. A primeira etapa envolveu a participação de professores da rede de ensino público e privado de Goiânia/Goiás/Brasil, que responderam a um questionário semiestruturado. Na segunda etapa foi realizada a análise do livro de Biologia adotado em três diferentes escolas na $3^{a}$ série do EM. Foi verificado que os professores destinam entre três e quatro aulas para a abordagem desse conteúdo, cujas principais dificuldades estão na falta de interesse dos estudantes, falta de tempo para preparação das aulas/atividades e falta de infraestrutura/materiais pedagógicos para abordar o assunto de forma prática. As estratégias/recursos didáticos mais utilizados são data-show, quadro, livro didático e vídeos; $25 \%$ dos professores realizam atividades práticas. Nos livros analisados, esse conteúdo é abordado de forma breve e superficial. Com isso, percebe-se a necessidade de que a decomposição e ciclagem de nutrientes sejam trabalhados de forma contínua e contextualizada com a realidade do estudante, permitido a relação e a compreensão dos processos que tornam o ecossistema dinâmico.
\end{abstract}

Palavras-chave

ciclos biogeoquímicos; ensino de Biologia; prática pedagógica; recursos didáticos

Samanta Oliveira da Silva* Cibele Pimenta Tiradentes** Solange Xavier dos Santos ${ }^{* * *}$

Mestra em Recursos Naturais do Cerrado (RENAC). Professora na Educação Básica do Município de Goiânia, Goiânia/Goiás-Brasil.

E-mail:samantabiologa@gmail.com Orcid: 0000-0002-9950-1192.

** Mestra em Ciências Ambientais e Saúde. Professora adjunta do Curso de Ciências Biológicas. Universidade Estadual de Goiás, Campus de Ciências Exatas e Tecnológicas (UEG/CCET), Anápolis/Goiás-Brasil.

E-mail: cibele.tiradentes@ueg.br. Orcid: 0000-0002-4328-0191.

*** Pós-Doutora em Recursos Genéticos e Biotecnologia. Professora adjunta do Curso de Ciências Biológicas e Orientadora no Programa de

Pós-graduação em Recursos Naturais do Cerrado (RENAC). Universidade Estadual de Goiás, Campus de Ciências Exatas e Tecnológicas (UEG/CCET), Anápolis/Goiás-Brasil.

E-mail:solxav@yahoo.com.br

Orcid: 0000-0002-3397-0885.

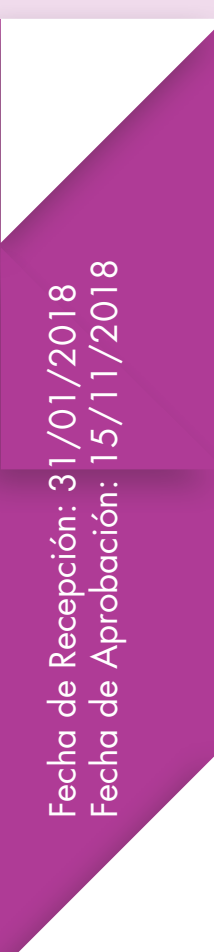




\section{Resumen}

El artículo tuvo como objetivo verificar cómo el contenido involucrando descomposición y ciclo de nutrientes es abordado en la Enseñanza Media (EM) por el profesor y en el libro didáctico. La primera etapa involucró la participación de profesores de la red de enseñanza pública y privada de Goiânia / Goiás, que respondieron a un cuestionario semiestructurado. En la segunda etapa se realizó análisis del libro de Biología adoptado en tres diferentes escuelas en el tercer año de la EM. Los profesores destinan entre tres y cuatro clases para abordar el contenido, cuyas principales dificultades están en la falta de interés de los estudiantes, falta de tiempo para la preparación de las clases / actividades y falta de infraestructura / materiales pedagógicos para abordar el asunto de forma práctica. Las estrategias / recursos didácticos más utilizados son; video beam, tablero, libro didáctico y vídeos. Sólo $25 \%$ de los profesores realizan actividades prácticas. En los libros analizados, ese contenido es abordado de forma breve y superficial. Con lo anterior, se percibe la necesidad de que los contenidos de descomposición y ciclo de nutrientes sean trabajados de forma continua y contextualizados con la realidad del estudiante, permitiendo la relación y la comprensión de los procesos que hacen el ecosistema dinámico.

Palabras clave

ciclos biogeoquímicos; enseñanza de biología; práctica pedagógica; recursos didácticos

\section{Abstract}

The purpose of the paper was to verify how the content involving decomposition and nutrient cycling is addressed in Secondary Education (SE) by the teacher and in the textbook. The first stage involved the participation of teachers from the public and private education network of Goiânia, Goiás, who answered a semi-structured questionnaire. In the second stage, the Biology book used in three different schools during the third year of SE was analyzed. Teachers devote three to four classes to address the content, the main difficulties of which are the student's lack of interest, lack of time to prepare the classes/activities, and lack of infrastructure/pedagogical materials to address the issue in a practical way. The most used strategies/didactic resources are the video projector, the board, the textbook, and videos. Only $25 \%$ of teachers do practical activities. In the analyzed books, this content is addressed briefly and superficially. Based on this, we perceive the need to work on the decomposition and nutrient cycle contents continuously and contextualized with the reality of the student, thus allowing the relationship and understanding of the processes that make the ecosystem dynamic.

Keywords

biogeochemical cycles; biology teaching; teaching practice; didactic resources 


\section{Introdução}

No processo ensino-aprendizagem, cada estudante possui motivações e preferências ao aprender e ao se relacionar com o conteúdo; possui também ritmo próprio de aprendizagem e diferentes experiências (socialmente) vividas (Scarpato, 2004). Para Silva (2002) e Moraes e Varela (2007), o interesse nas disciplinas, por parte do estudante, depende de como o professor expõe o conteúdo, despertando interesse, intenso ou não, sobre os assuntos tratados em sala.

Apesar das novas tecnologias e instrumentos pedagógicos, na sala de aula, o livro didático ainda é o elo de "comunicação verbal" entre estudantes e professores, tanto no Ensino Fundamental e Médio, quanto na graduação (Silveira, 2009). Por essa razão, a forma superficial e complexa com que os conteúdos são trazidos nos livros didáticos e a falta de associação dos conteúdos ministrados frente à realidade na qual o estudante está inserido constituem fatores prejudicialmente significativos nesse processo (Vasconcelos, 2002; Vilela, 2007).

Ao trabalharem a decomposição com estudantes do Ensino Fundamental e Médio, Silva, Tiradentes e Xavier-Santos (2016) e Zômpero e Laburú (2010), perceberam que eles encontravam dificuldades em relacionar os agentes decompositores à decomposição da matéria orgânica, bem como de relacionar esse fenômeno à ciclagem de nutrientes. Contrariamente a isso, as Orientações Curriculares para o EM (Ministério da Educação [MEC], 2006) preconizam que a contextualização dos conteúdos de Biologia, aliada à realidade do estudante, leva a momentos de reflexão acerca da interação entre os seres vivos e o ambiente que os rodeia.

Diante disso, este trabalho teve por objetivo verificar como o conteúdo envolvendo a decomposição e ciclagem de nutrientes é abordado no EM, tanto pelo professor na sala de aula, quanto no livro didático de Biologia.

\section{Metodologia}

Esta é uma pesquisa exploratória, de caráter quali-quantitativo e foi desenvolvida em duas etapas. A primeira envolveu a participação de professores de Biologia do EM que atuam em instituições da rede pública e privada da cidade de Goiânia/Go. Os docentes foram selecionados a partir de seu interesse em participar da pesquisa, os quais responderam a um questionário composto por oito questões abertas e fechadas, que buscavam averiguar informações da sua formação profissional (nível de escolaridade e curso de formação) e da sua prática docente acerca do conteúdo de decomposição e ciclagem de nutrientes (quantidade de aulas; série/ano; dificuldades; recurso didáticos e uso de aulas práticas para abordar o conteúdo). Os dados oriundos dos questionários foram analisados com base na técnica da estatística descritiva (por meio de números absolutos), com o auxílio do software Excel ${ }^{\circledR} 2010$.

Aos participantes foi garantido o anonimato. Nas transcrições das suas respostas para o texto, foram retirados indicativos de reconhecimento dos sujeitos envolvidos na pesquisa, que foram identificados com a inicial $P$, seguida de um número: $P_{1}$ a $P_{8}$. Da mesma forma, foi utilizada a expressão 'professor' tanto para os participantes do sexo masculino, quanto feminino.

A segunda etapa da pesquisa focou em analisar o livro didático de Biologia acerca da abordagem do conteúdo referente à decomposição e ciclagem de nutrientes. Os livros selecionados são adotados para a $3^{a}$ série do EM por três professores (que participaram da primeira etapa da pesquisa) de diferentes instituições da rede estadual de ensino do município de Goiânia/Go. Tais livros foram tratados como L1, L2 e L3, respectivamente (Quadro 1). 
O L1 faz parte da coleção do Plano Nacional do Livro Didático [PNLD] 2012 (MEC, 2011 ) e foi analisado por estar sendo adotado naquele momento em uma das instituições de ensino pesquisadas, visto que, os livros do PNLD são válidos por três anos consecutivos. L2 e L3 fazem parte do PNLD 2015 (MEC, 2011 ; 2014). Cada uma dessas obras constitui um volume de uma coleção distinta, composta de três volumes, cada volume destinado a uma das três séries do EM.

A análise focou no conteúdo de decomposição, biodegradação e ciclagem de nutrientes, considerando os critérios discriminados no quadro 2. Esses critérios foram propostos conforme a disposição do conteúdo nas Diretrizes Curriculares Nacionais para o Ensino Médio [DCNEM]) - documento utilizado para nortear o conteúdo das disciplinas do Ensino Médio (MEC, 2013); Matriz de Referência do Exame Nacional do Ensino Médio-ENEM (MEC, 2009); Currículo Referência da Rede Estadual de Educação de Goiás (Secretaria de Educação, Esporte, Cultura e Lazer, 2015) e nos trabalhos de Vasconcelos e Souto (2003), Espínola (2007), Rosa e Mohr (2010), Batista, Cunha e Cândido (2010) e G. Silva (2014).

\section{Resultados e discussão}

\section{A prática docente}

As respostas obtidas a partir da aplicação do questionário, na primeira etapa da pesquisa, permitiram avaliar como o conteúdo envolvendo a decomposição e ciclagem de nutrientes é abordado na sala de aula. Dos dez professores de Biologia abordados, oito aceitaram participar da pesquisa, sendo dois atuantes na rede particular e seis na rede pública de ensino.

Todos os professores pesquisados são graduados em Ciências Biológicas, ainda que a titulação máxima tenha variado entre a graduação (cinco professores); especialização (dois) e doutorado (um). Maranhão (2000) chama a atenção para a importância da formação do professor, salientando a existência de uma relação entre o nível de escolaridade do docente e o desenvolvimento do conhecimento do estudante. Segundo Dos Santos, Pereira, Tiradentes e Xavier-Santos (2017) é fundamental pensar tanto a formação inicial quanto a continuada no processo de ensino aprendizagem, possibilitando aos professores de Ciências da Natureza desenvolver uma maior capacidade crítica, reflexiva e transformadora. fato dos decentes serem graduados em Ciências Biológicas é favorável para que estabeleçam com mais facilidade as relações entre o conteúdo estudado e o dia a dia do estudante, favorecendo o sucesso no ensino aprendizagem.

Ao serem indagados sobre a quantidade de tempo (aulas) que destinam à abordagem do conteúdo, quatro professores disseram utilizar entre três e quatro aulas; outros dois professores utilizam entre uma e duas aulas; um alegou que não aborda esse conteúdo; e o último utiliza entre quatro e cinco aulas, porém isso depende da série em que se está trabalhando e em qual conteúdo está inserida a ciclagem de nutrientes. 
Quando foram questionados sobre em que momento do ano letivo eles abordam o conteúdo de ciclagem de nutrientes, cinco disseram que é na $3^{a}$ série do EM (quatro no segundo semestre e um no primeiro bimestre, durante as aulas sobre ciclos biogeoquímicos); um disse abordar na $1^{a}$ série do EM (no $1^{\circ}$. bimestre); um disse na $2^{a}$ série do $E M$, quando se trabalha o Reino Fungi; um professor não aborda.

A maioria dos professores (cinco) respondeu que aborda a ciclagem de nutrientes durante as aulas sobre os ciclos biogeoquímicos. Esse conteúdo, geralmente é abordado na $3^{a}$ série do EM, pois está agregado aos estudos de Ecologia. No Currículo Referência das escolas estaduais do município de Goiânia, o tópico "ciclos biogeoquímicos" está inserido no quarto bimestre da $3^{a}$ série do EM. Entretanto, por ser considerado um tema complexo, cada ciclo envolvido na ciclagem de nutrientes é explicado individualmente e dissociado da importância e participação de cada ciclo na manutenção do ecossistema.

Quando indagados sobre as dificuldades encontradas para se ministrar esse conteúdo, os professores marcaram mais de uma opção para esta pergunta e as queixas concentraram-se no desinteresse dos estudantes (três), falta de tempo para a preparação das aulas/ atividades (três), falta de infraestrutura e/ou materiais pedagógicos para abordar o assunto de forma prática (três), falta de tempo para execução das aulas (dois), complexidade do assunto, falta de conhecimento e ou formação na área em questão (dois).

A falta de interesse demonstrada pelos estudantes tem fragilizado o ensino de Biologia. De acordo com Silva, Morais e Cunha (2011), não se pode culpar apenas os estudantes por este fracasso, o professor também é responsável pela motivação no processo de aprendizagem. Essa desmotivação é reflexo da falta de organização escolar, bem como das metodologias adotadas pelos professores para intermediar o conhecimento.

Além do desinteresse dos estudantes, a falta de tempo para a preparação/execução de atividade e a falta de infraestrutura adequada para a realização de aulas práticas prejudicam o ensino aprendizagem. Tais afirmações corroboram os estudos de Silva, Morais e Cunha (2011) e Vieira, Silva, Peres e Alves (2010), nos quais a falta de tempo para preparação/execução de atividade e a falta de infraestrutura adequada para a realização de aulas práticas são também as maiores dificuldades encontradas pelos professores para ministrar os conteúdos de Biologia.

Questionados sobre os recursos e estratégias didáticas mais utilizadas para ministrar o conteúdo, os professores marcaram mais de uma opção, podendo-se listar: data show (sete), quadro negro ou branco (sete), livro didático (seis), vídeos (três), aulas práticas (dois-sendo realizadas em sala de aula e em laboratório de ciências), revistas e jornais (um). Nenhum docente mencionou utilizar jogos, livros paradidáticos, cartazes feitos por eles ou pelos estudantes, ou ainda páginas na internet dedicadas ao assunto.

No ambiente escolar podem ser utilizados diversos recursos didáticos para o ensino de Biologia; entretanto, é importante uma escolha adequada do material pedagógico para que se alcance os objetivos de ensino do conteúdo (Souza, 2007), e a diversificação dessas metodologias é necessária para o desenvolvimento cognitivo do estudante (Zuanón, Diniz e Nascimento, 2010). O ideal seria que o professor adotasse aulas teórico-práticas para incentivar o desenvolvimento do conhecimento científico e melhorar a capacidade intelectual do estudante, fazendo com que ele desenvolva conhecimento crítico acerca do conteúdo aprendido (Silva, Morais e Cunha, 2011 ). 
Ainda que seja difícil inovar as estratégias de ensino, é possível realizar aulas práticas sem a necessidade de laboratório, visto que existem diversas atividades simples que podem ser realizadas na própria sala de aula. Associada a essa estratégia didática, pode-se fazer o uso de vídeos, cartazes, jogos, entre outros, que também irão estimular o trabalho coletivo e a troca de conhecimento entre os estudantes (Pontecorvo, Ajello e Zucchermaglio, 2005).

Quando solicitados a mencionar brevemente as atividades práticas que costumam realizar acerca desse conteúdo, apenas quatro professores atenderam à solicitação, ainda que apenas três relataram as atividades realizadas com os estudantes. Segundo eles, essas atividades são realizadas no próprio ambiente escolar e nos seus arredores, partindo da observação de fungos, decomposição de frutos ao longo das semanas ou na construção de terrários, conforme as respostas transcritas abaixo:

(P5) "Coleta sistemática de fungos na própria escola e nas redondezas da comunidade escolar. Já visitamos uma lavoura de soja e observamos as raízes destas leguminosas a fim de encontrar bactérias 'nitrificantes'."

(P6) "Observação, análise e registro fotográfico dos efeitos da decomposição de frutos ao longo da semana e a confecção de um relatório."

(P8) "Realizo atividades simples de observação em relação a reciclagem, como: criar um espaço pequeno com terra e deixar os alunos colocarem alguns tipos de materiais, restos de alimentos, isopor, madeira e papel."

O Professor P5, com essa atividade, busca explicar como as bactérias estão envolvidas no ciclo do nitrogênio e como elas auxiliam no desenvolvimento das plantas. Essa atividade possibilita que o estudante compreenda que as bactérias são capazes de assimilar esse elemento da atmosfera e transformá-lo em nitratos para que possa ser absorvido e utilizado pelas plantas na fabricação de suas proteínas e de seus ácidos nucléicos, auxiliando no seu crescimento. Essas informações permitem ao professor explicar o ciclo do nitrogênio e a importância das bactérias na manutenção do equilíbrio ecossistêmico.

Os Professores P6 e P8, ao levarem os estudantes a observarem a decomposição dos frutos ou ao criarem um terrário com restos de materiais orgânicos e inorgânicos, conseguem explicar como o processo de decomposição está diretamente ligado à ciclagem de nutrientes e, também, explicar como a liberação de nutrientes está relacionada ao equilíbrio ecossistêmico.

Assim, ao abordar o conteúdo sobre cadeias alimentares, o professor pode inserir o ser humano como consumidor e produtor de lixo, trabalhando o destino correto do lixo e como ocorre o processo de decomposição. Ao falar sobre decomposição, ele pode abordar a importância da relação dos fungos e bactérias com a ciclagem de nutrientes; como a destinação das fezes humanas pode trazer implicações para a saúde, e ainda relacionar as ações antrópicas à reciclagem da matéria. Enfim, o professor, como intermediário do conhecimento, 
deve promover esses momentos de reflexão, estabelecendo relações com o cotidiano do estudante e promover o conhecimento (Malucelli, 2007).

Ao solicitar que os professores fizessem sugestões ou solicitações de como essa abordagem poderia ser incrementada, apenas três o fizeram, cujas respostas são transcritas abaixo:

(P4) "Investimento por parte dos programas de pós-graduação em possibilitar uma formação continuada aos professores da educação básica para se trabalhar estes conceitos na sala de aula de uma maneira menos abstrata e que venha condizer com a realidade do nosso público-alvo."

(P6) "Trabalhar a ciclagem de nutrientes abordando o desenvolvimento sustentável, a agroecologia e estimular a realização da compostagem nas escolas."

(P8) "Gostaria muito de um trabalho específico na área em parceria com a Universidade."

Diante das solicitações, percebe-se que o professor deseja parcerias com instituições de ensino superior por meio de programas de cooperação, tais como o Programa Institucional de Bolsas de Iniciação à Docência (PIBID), os mestrados profissionais em ensino, entre outros, que podem contribuir ou auxiliar o professor no desenvolvimento da sua prática pedagógica por meio do estreitamento das relações entre o ensino básico e a universidade.

\section{O livro didático}

Como demonstrado anteriormente, o livro didático é um dos recursos mais utilizados pelos professores envolvidos nessa pesquisa e, como relatado em outros trabalhos, tem sido um dos principais norteadores da aula ministrada pelo docente. Por isso é importante que seja feita uma análise dos conteúdos que
- livro apresenta (Giannotti, 2002; Selles e Ferreira, 2004; Fracalanza, 2006).

A análise dos livros didáticos de Biologia, indicados pelos professores entrevistados, mostrou que todos os livros abordam o conteúdo de decomposição e ciclagem de nutrientes; também, que o texto possui linguagem clara sobre o conteúdo. Cada uma dessas obras constitui um volume de uma coleção distinta, composta de três volumes, cada volume destinado a uma das três séries do EM. Os livros L1 e L2 apresentam-se divididos em capítulos/unidades subdivididos em seções/temas, enquanto que L3 é subdividido em capítulos.

$O$ livro $L 1$ é dividido em três unidades temáticas ( $A, B$ e $C$ ), sendo a Unidade $C$ a que traz o conteúdo da decomposição e ciclagem de nutrientes. $O$ livro $L 2$ é dividido em sete unidades temáticas e a sétima aborda os conceitos analisados. $O$ livro L3 é dividido em quatro unidades temáticas, sendo a quarta a tratar os assuntos analisados.

Dos critérios analisados, o Conteúdo Geral foi o que apresentou maior necessidade de reformulação ou aprimoramento. $\mathrm{Na}$ abordagem sobre ciclos biogeoquímicos, os livros L1, L2 e L3 fazem referência à "ciclagem de nutrientes", abordando o conceito de decomposição e a função dos decompositores ao longo dos ciclos dos nutrientes de forma sucinta. O livro L1 informa a importância da reciclagem de nutrientes e estabelece a relação desse fenômeno com os ciclos biogeoquímicos. $\bigcirc$ livro L2 não deixa clara a terminologia para a palavra 'biogeoquímico', sua linguagem é complexa e direta; assim, para que o estudante compreenda é necessário conhecimento prévio de conceitos como abiótico e biótico.

O livro L3 contextualiza a abordagem da ciclagem de nutrientes por meio do ciclo do carbono, explicitando a diferença entre sua 
absorção através da fotossíntese e a sua emissão pela respiração. Para que o estudante compreenda a relação entre fotossíntese, respiração e a presença de gás carbônico na atmosfera, é importante o conhecimento prévio acerca dos processos envolvidos (fotossíntese e respiração). Sem o auxílio do professor e apenas se fazendo a leitura, o estudante não compreenderia a relação da respiração e fotossíntese com a ciclagem de nutrientes.

Todos os livros, ao abordar os ciclos (água, rochas, carbono, nitrogênio, fósforo, potássio, cálcio, etc.), não deixam clara a relação entre eles, dando a impressão de que na natureza cada um ocorre isoladamente do outro, quando na verdade todos os ciclos estão interligados devido às relações ecológicas estabelecidas entre produtores, consumidores e decompositores (teias e cadeias alimentares), os quais participam ativamente da reciclagem de nutrientes no ecossistema.

Compreender a ligação dos eventos naturais que ocorrem no ecossistema possibilita ao estudante ter resposta a perguntas como: "Qual a relação entre cada ciclo?", "Qual a função dos fungos e bactérias nos ciclos biogeoquímicos?", "Qual a influência da produção do lixo nos ciclos biogeoquímicos?", "Quais ações antrópicas mais influenciam a ciclagem de nutrientes?".

Ao compreender as transformações que ocorrem no ecossistema, o estudante desenvolve consciência crítica e percebe que suas ações podem influenciar a manutenção do equilíbrio ecossistêmico. Compreende que cada ação humana desencadeia uma reação no meio natural e que a Biologia, apesar de complexa, não é uma ciência "decorativa" ou com nomes difíceis, mas sim uma ciência que compreende as diferentes formas de vida e que está associada ao seu dia a dia (Silva, 2014).

Em todos os livros, o papel dos decompositores foi um dos itens melhor abordados. Os três títulos analisados mencionaram a participação dos seres vivos na decomposição da matéria orgânica, como serapilheira, restos de animais mortos e excretas de animais; assim mesmo, ressaltaram a importância dos fungos e bactérias na ciclagem dos nutrientes, bem como a relevância da presença desses microrganismos para a manutenção do ecossistema. Nesse sentido, os livros analisados descreveram claramente quem são os decompositores e sua relação com a ciclagem de nutrientes, tal como destacado nas transcrições a seguir:

(L1) "Ao morrer, produtores e consumidores dos diversos níveis tróficos servem de alimento a certos fungos, bactérias e diversos animais invertebrados e protozoários. A decomposição é importante por permitir a reciclagem dos átomos de elementos químicos, que podem voltar a fazer parte de outros seres vivos."

(L2) "Seres vivos que decompõem a matéria orgânica dos organismos mortos obtendo nutrientes e energia, como fungos e bactérias, são chamados decompositores. São responsáveis pela reciclagem dos elementos químicos, disponibilizando-os novamente para outros seres vivos." 
(L3) "Isso ocorre, principalmente, pela ação de fungos e bactérias que vivem no solo e na água. Podemos compreender o papel fundamental dos decompositores ao promover a reciclagem da matéria orgânica contida nos cadáveres, excretas e fezes dos animais."

O livro L1 inclui animais invertebrados e protozoários. De fato, os pequenos invertebrados, que constituem uma parte importante da fauna do solo, contribuem com a decomposição, digerindo proteínas e glicídios simples, enquanto alguns protozoários atuam como parasitas ou predadores, participando do ciclo da matéria e contribuindo com a estrutura do solo em função dos nutrientes que são disponibilizados (Correia e Andrade, 1999).

A relação entre os decompositores e outros organismos foi expressa nas representações da cadeia alimentar e na distribuição de energia ao longo do nível trófico, conforme relata o livro L3:

Em média, apenas 10\% da energia de um nível passa para o nível seguinte, [...] os resíduos ficam novamente disponíveis para a cadeia alimentar pela ação dos decompositores, sendo utilizados mais uma vez pelos produtores, [...] a matéria de um ecossistema nunca se esgota e está em permanente reciclagem.

A contextualização é um dos critérios mais relevantes para o processo de aprendizagem, pois permite traçar uma conexão entre o conteúdo e a rotina do estudante. Nesse sentido, os livros apresentam textos que fazem associações com assuntos do dia a dia, e esses podem ser explorados em sala.

O livro L1, ao abordar questões que envolvem o excesso de gases polventes na atmosfera, faz um alerta quanto aos prejuízos que esses gases podem causar ao homem, se essas taxas não forem reduzidas:
Já há registros de desertos se expandindo, cidades costeira inundadas e grandes alterações climáticas. [...] se os gases responsáveis pelo efeito estufa continuarem a se acumular na atmosfera, devemos esperar uma elevação de até $4 \mathrm{C}$ na temperatura média mundial, nos próximos 50 anos.

Ao abordar o ciclo da água, o livro L2 traz um texto que aborda o uso consciente desse recurso: "Por ser um recurso essencial para os seres vivos e para a manutenção dos ecossistemas, a utilização consciente da água é tema de campanhas do governo brasileiro e UNESCO [...]."

O livro L3, ao abordar o ciclo do oxigênio ressalta a importância de medidas mitigativas para conter a destruição da camada de ozônio, visto que para os seres vivos a camada de ozônio é essencial, pois impede a entrada de radiação ultravioleta (UV) que pode causar prejuízo não apenas aos ecossistemas, como também aos seres humanos, conforme relatado no livro L3: "esse tipo de radiação aumenta a incidência de câncer de pele (por causa do aumento das taxas de mutações), de catarata (por lesões no cristalino) e de prejuízos ao sistema imunológico".

Estabelecer a associação do conteúdo estudado com os costumes e hábitos dos estudantes permite a formação do cidadão crítico. É importante ressaltar que as leituras complementares auxiliam o estudante a observar o mundo, permitindo o entendimento dos fenômenos próximos. Compreender que um assunto estudado está presente no seu dia a dia é a descoberta do conhecimento científico.

Junior e Barbosa (2009) afirmam que a escola é formadora de cidadãos plenos, conscientes, críticos e éticos. Portanto, os concluintes do EM devem ser dotados de habilidades e competências que os levem a acompanhar 
as mudanças biotecnológicas e científicas, permitindo a busca por respostas complexas e sua plena participação nos avanços científicos.

A utilização de ilustrações e imagens que representem esquematicamente os processos envolvidos na decomposição e ciclagem de nutrientes é de suma importância. As obras analisadas não apresentaram problemas graves no que se refere à qualidade das figuras, como nitidez e cores. Elas são atrativas, coloridas, oportunas e relacionadas ao conteúdo. Em geral, são representações esquemáticas simplificadas dos textos, e possuem título curto, mas explicativo.

De acordo com Coutinho, Soares, Braga e Chaves (2010), imagens de boa qualidade, com legendas independentes e autoexplicativas são recursos fundamentais no processo de ensino aprendizagem, pois incentivam a curiosidade do estudante. $O$ livro L3 diferencia os decompositores quanto a bactérias e fungos; nos livros L1 e L2 as bactérias são ilustradas em forma de bastonetes, enquanto os fungos ilustrados estão na sua forma anamorfa (composta de hifas vegetativas) ou são corpos de frutificação (cogumelos).

A falta de diferenciação dos decompositores envolvidos na ciclagem de nutrientes pode ocasionar uma série de erros, visto que a forma como esses seres vivos são ilustrados dificulta a diferenciação entre bactérias e fungos, principalmente, quando bactérias e a forma anamorfa do fungo são ilustradas em uma mesma figura. De acordo com Vasconcelos e Souto (2003), é preciso que as figuras sejam claras e objetivas, o suficiente para não confundir o estudante, pois quando não utilizadas de forma coerente e clara, esse recurso pode prejudicar o aprendizado.

Todos os livros informam na legenda das figuras sobre a presença ou ausência de escala de tamanho e o uso de cores 'fantasias'; entretanto, falta legenda descritiva quanto ao conteúdo de decomposição e ciclagem de nutrientes. Quanto à relação da figura com o texto, o livro L2 deixa a desejar, cabendo ao leitor encaixá-las no texto. Para Costa (2005), a utilização de ilustração e imagem constitui um bom recurso para auxiliar na aprendizagem desde que estejam relacionadas com o texto escrito e possuam caráter científico.

Quanto ao conteúdo complementar, todos os livros apresentaram atividades de fixação. Em relação a atividades práticas, apenas L2 e L3 sugeriram essas atividades. $O$ livro L3 fornece uma atividade que procura por meio da investigação enriquecer o conhecimento do estudante acerca do ecossistema, a partir da montagem de um terrário e da observação dos processos envolvidos na ciclagem de nutrientes. A atividade sugerida em L2 trata do crescimento populacional, e não acrescenta nenhum conhecimento acerca do assunto em foco.

A realização de atividades práticas, especialmente as experimentais de cunho investigativo, é importante para o desenvolvimento cognitivo do estudante, elas aproximam a teoria da realidade do estudante, visto que envolvem a utilização 
de materiais, a elaboração de hipóteses e a vivência do experimento (Rosito, 2003; Zanon e Freitas, 2007; Coquidé, 2008). O despertar da curiosidade do estudante torna as aulas interessantes e motiva o ensino aprendizagem. Para Panarari-Antunes, Defani e Gozzi (2009) é fundamental que toda a sugestão de atividade seja bem elaborada (descrita), para que professores e estudantes desenvolvam de forma clara e objetiva o experimento proposto.

Todos os livros sugerem leitura complementar, a maioria dos textos complementares é apresentada ao longo dos capítulos, fazendo relação com o conteúdo dos ciclos biogeoquímicos. Como diferencial, os livros L2 e L3 trazem, ao final, uma lista de sugestões de livros, artigos, filmes e sites disponíveis na internet para aprofundar os conhecimentos acerca dos conteúdos estudados.

A leitura complementar representa uma informação adicional do conteúdo didático estudado que pode promover espaços privilegiados de discussões e debates, deixando claro aos estudantes que o assunto abordado pode ser empregado em situações cotidianas e práticas. Além disso, faz com que essa perca um pouco do seu caráter abstrato e complexo, tornando mais fácil a assimilação do conteúdo. De acordo com Silveira (2009) e Batista, Cunha e Cândido (2010) o texto complementar pode ser eficiente em resolução de problemas no ensino aprendizagem quando em sala de aula essas leituras retratem temas relacionados ao seu mundo vivencial, instigando a curiosidade e atenção do estudante.

\section{Considerações Finais}

O conteúdo envolvendo a decomposição e ciclagem de nutrientes é abordado pelo professor ao longo de três a quatro aulas, dependendo do desenvolvimento da turma.
Em geral os docentes utilizam preferencialmente aulas teóricas expositivas/explicativas, com o auxílio do data-show, quadro e livro didático.

Entre as limitações para se trabalhar esse conteúdo está o desinteresse por parte dos estudantes, a falta de infraestrutura e de tempo para a preparação e para a execução de atividades diferenciadas, sendo a maioria dos professores não faz uso de atividades práticas. Entre aqueles que fazem uso dessa modalidade didática, a falta de infraestrutura adequada para o desenvolvimento de atividades acaba restringindo à realização de atividades simples, utilizando-se de materiais de fácil acesso; sendo mais comumente citadas as atividades de acompanhamento da decomposição de frutos e a construção de terrários.

Os três livros didáticos utilizados na amostragem, ainda que componham o PNDL (2012 e 2015) e tenham sido avaliados antes de chegarem às escola apresentam algumas fragilidades: há carência de informações sobre a ciclagem de nutrientes, falta de contextualização dos ciclos biogeoquímicos com a decomposição e ciclagem de nutrientes, falta de contextualização como o cotidiano do estudante, falta de coerência entre texto e figuras, ausência de escalas nas figuras e de sugestões de atividades práticas. Esses aspectos devem ser melhorados e reformulados, a fim de permitir ao professor e ao estudante uma reflexão crítica sobre as relações que envolvem o meio em que vivem com o conteúdo abordado.

Além disso, sugere-se que a abordagem dos conteúdos relacionados à decomposição e ciclagem de nutrientes deva ocorrer de forma contínua e que o professor deva estabelecer as relações entre a decomposição e a ciclagem de nutrientes, pois é importante a compreensão dos processos que tornam o ecossistema dinâmico. 


\section{Referências}

Batista, M. V. A., Cunha, M. M. S. e Cândido, A. L. (2010). Análise do tema virologia em livros didáticos de biologia do ensino médio. Revista Ensaio, 1 (12), 145-158. Recuperado de http://www.scielo.br/pdf/epec/v12n1/1983-21 17-epec-12-01-00145.pdf.

Bröckelmann, R. H. (2013). Conexões com a Biologia. 1. São Paulo: Moderna.

Correia, M. E. F., e Andrade, A. G. (1999). Formação de serapilheira e ciclagem de nutrientes. Em G. A Santos e F. A Camargo. (Ed.). Fundamentos da matéria orgânica do solo: ecossistemas tropicais e subtropicais (pp. 197-225). Porto Alegre, Brasil: Gênesis.

Coquidé, M. (2008). Um olhar sobre a experimentação na escola primária francesa. Ensaio, 10 (1), 1-18. Recuperado de https://seer.ufmg.br/index.php/ensaio/ article/view/8660/6600.

Costa, C. (2005). Educação, imagem e mídias. São Paulo: Cortez.

Coutinho, F. A., Soares, A. G. Braga, S. A. M., e Chaves, A. C. L. (2010). Análise do valor didático de imagens presentes em livros de biologia para o ensino médio. Revista Brasileira de Pesquisa em Educação em Ciências, 10 (3), 1-18.

Dos Santos, R. Pereira, W. Tiradentes, C., e Xavier-Santos, S. (2017). A história da formação de professores de Ciências da Natureza dos anos finais do Ensino Fundamental em Goiás. Revista de la Facultad de Ciencia y Tecnología-Tecné, Episteme y Didaxis, TED, 41, 109-127.

Espínola, C. R. R. (2007). Aves na Escola: análise de livros didáticos do ensino fundamental. 63f. Monografia (Graduação em Ciências Biológicas) - Centro de Ciências Biológicas, Universidade Federal de Santa Catarina, Florianópolis.

Fracalanza, H. (2006). O ensino de ciências no Brasil. Em H. Fracalanza, J. Megid-Neto (Ed.). O livro didático de ciências no Brasil. (pp. 58-60). Campinas: Komedi.

Giannotti, S. M. (2002). O ensino de matemática e o livro didático na voz dos professores: um estudo de caso. 2002. 132 f. Dissertação (Mestrado em Educação). Programa de Pós-Graduação em Educação. Universidade Estadual de Londrina, Londrina.

Junior, A. N. S. e Barbosa, J. R. A. (2009). Repensando o Ensino de Ciências e de Biologia na Educação Básica: o Caminho para a Construção do Conhecimento Científico e Biotecnológico. Democratizar, 3 (1), 1-15.

Linhares, S. e Gewandsznajder, F. (2014). Biologia Hoje: Genética, Evolução e Ecologia. 2. São Paulo: Ática.

Malucelli, V. M. B. (2007). Formação dos professores de Ciências e Biologia: reflexões sobre os conhecimentos necessários a uma prática de qualidade. Estudos de Biologia, Ambiente e Diversidade, 66 (29), 113-116. 
Maranhão, E. F. (2000). A qualidade no trabalho docente. Em Seminário Escola Jovem: Um Novo Olhar Sobre o Ensino Médio. Net, Brasília, 6. Recuperado http://portal.mec.gov. $\mathrm{br} / \mathrm{seb} /$ arquivos/pdf/qualidade_trab. pdf.

Ministério da Educação. (2006). Orientações Curriculares para o Ensino Médio. Parte II: Ciências da Natureza, Matemática e suas Tecnologias. Brasília: Autor. Recuperado de: http://portal.mec.gov.br/seb/arquivos/pdf/ book_volume_02_internet.pdf.

. (2009). Matriz de Referência do ENEM 2009. Brasília: Autor. Recuperado http:// sitedoenem.com.br/enem/baixar-matriz-de-referencia-enem-2013.html.

. (2011). Guia de livros didáticos: PNLD 2012-Biologia. Brasília: Autor.

. (2013). Diretrizes Curriculares Nacionais para o Ensino Médio. Brasília: Autor. Recuperado http://portal.mec.gov.br/docman/ julho-2013-pdf/13677-diretrizes-educacao-basica-2013-pdf/file.

. (2014). Guia de livros didáticos: PNLD 2015-Biologia: ensino médio. Brasília: Autor.

Moraes, C. R. e Varela, S. (2007). Motivação do aluno durante o processo de ensino-aprendizagem. Revista Eletrônica de Educação, 1 (1), 1-15.

Panarari-Antunes, R. S. Defani, M. A. e Gozzi, M. E. (2009). Análise de atividades experimentais em livros didáticos de ciências. Em: ix Congresso Nacional de Educação, iii Encontro Sul Brasileiro de Psicopedagogia. Curitiba, 2009. D. S Vosgerau, R. T Ens, e V. L Casteleins. (Ed.) Anais... Curitiba: Pontifícia Universidade Católica do Paraná. (CD-ROM).

Pontecorvo, C., Ajello, A. M., e Zucchermaglio, C. (2005). Discutindo se aprende: interação social, conhecimento e escola. Porto Alegre: Arthmed.
Rosa, M. e Mohr, A. (2010). Os fungos na escola: análise dos conteúdos de micologia em livros didáticos do ensino fundamental de Florianópolis. Experiências em Ensino de Ciências, 5 (3), 95-102.

Rosito, B. A. (2003). O ensino de ciências e a experimentação. Em Moraes, R. (Ed.). Construtivismo e ensino de ciências: reflexões epistemológicas e metodológicas. Porto Alegre: EDIPUCRG, 195-208.

Scarpato, M. (2004). Procedimento de Ensino: Um Ato de Escolha na Busca de uma Aprendizagem Integral. São Paulo: Avercamp.

Secretaria de Educação, Esporte, Cultura e Lazer. (2015). Currículo Referência da Rede Estadual de Educação de Goiás. Goiânia: Seduce.

Selles, S. E. e Ferreira, M. S. (2004). Influências histórico-culturais nas representações sobre as estações do ano em livros didáticos de ciências. Ciência \& Educação, 1 (10), 101 110.

Silva, A. C. (2014). Análise do conteúdo de fungos nos livros didáticos de biologia do ensino médio indicados pelo programa nacional do livro didático 2012. 2014. 80f. Monografia (Graduação em Ciências Biológicas - Modalidade Licenciatura)-Instituto Federal de Educação, Ciência e Tecnologia, Campus São Paulo, São Paulo.

Silva, G. A. (2002). Motivação: em busca do conhecimento. Cadernos da FUCAMP, 1 (1), 135-142.

Silva, F. S. S. Morais, L. J. O. e Cunha, I. P. R. (2011). Dificuldades dos professores de Biologia em ministrar aulas práticas em escolas públicas e privadas do município de Imperatriz (MA). Educação, Políticas Públicas e Sociedade, 1 (1), 135-149. 
Silva, S. O., Tiradentes, C. P. e Xavier-Santos, S. (2016). A decomposição de excrementos: uma ferramenta de educação científica e ambiental acerca da ciclagem de nutrientes. 2016. Dissertação (Mestrado em Recursos Naturais do Cerrado)Universidade Estadual de Goiás, Anápolis, Goiás.

Silveira, A. C. R. (2009). O papel das leituras complementares nos livros didáticos de Física. 2009. Dissertação (Mestrado em Ensino de Ciências e Matemática). Pontifica Universidade Católica de Minas, Belo Horizonte.

Souza, S. E. (2007). O uso de recursos didáticos no ensino escolar. Em: I Encontro de Pesquisa em Educação, Iv Jornada de Prática de Ensino, XIII Semana de Pedagogia da UEM: "Infância e Práticas Educativas". Anais... (pp. 110-114). Maringá, PR, Recuperado http://www.dma.ufv.br/downloads/MAT\%20103/2014-II/Rec\%20 didaticos\%20-\%20MAT\%20103\%20-\%202014-II.pdf.

Vasconcelos, C. S. (2002). Construção do conhecimento em sala de aula. São Paulo: Lebertad.

Vasconcelos, S. D. e Souto, E. (2003). O livro didático de ciências no ensino fundamental - proposta de critérios para análise do conteúdo zoológico. Ciência \& Educação, 1 (9), 93-104.

Vieira, F. L. Silva, G. M. Peres, J. P. S. e Alves, E. D. L. (2010). Causas do desinteresse e desmotivação dos alunos nas aulas de Biologia. Universitas Humanas, 7 (1/2), 95-109.

Vilela, M. R. (2007). A produção de atividades experimentais em genética no ensino médio. 2007. 50 f. Monografia (Especialização em Ensino de Ciências por Investigação)-Universidade Federal de Minas Gerais, Belo Horizonte.

Zanon, D. A. V. e Freitas, D. (2007). A aula de ciências nas séries iniciais do ensino fundamental: ações que favorecem a sua aprendizagem. Ciências \& Cognição, 10 (1), 93-103.

Zômpero, A. F. e Laburú, C. E. (2010). A decomposição da matéria orgânica nas concepções de alunos do ensino fundamental: aspectos relativos à educação ambiental. Experiências em Ensino de Ciências, 1 (5), 67-75.

Zuanón, Á. C. A. Diniz, R. H. S. e Nascimento, L. H. (2010). Construção de jogos didáticos para o ensino de Biologia: um recurso para integração dos alunos à prática docente. Revista Brasileira de Ensino de Ciência e Tecnologia, 3 (3), 49-59.

\section{Para citar este artículo}

Oliveira da Silva, S. Pimienta, C. Xavier-Santos, S. (2019). Decomposição e ciclagem de nutrientes: uma análise da abordagem do livro didático e da prática docente no ensino médio. Tecné, Episteme y Didaxis: TED, 45, 57-70. 